\title{
O DIREITO E RECONHECIMENTO DE COMUNIDADE QUILOMBOLA EM MANAUS
}

\section{LAW AND COMMUNITY RECOGNITION QUILOMBOLA IN MANAUS}

\author{
${ }^{1}$ Aldrin Bentes Pontes \\ ${ }^{2}$ Joyce Karoline Pinto Oliveira Pontes
}

\section{RESUMO}

O presente artigo propõe uma reflexão sobre a história do reconhecimento de terras quilombolas no Brasil, especificamente na capital amazonense, sem esquecer-se de pontuar os fatos históricos ocorridos no Brasil. Quando se fala em reconhecimento oficial de terras das comunidades quilombolas, não se pode deixar a cultura desses povos de lado, mas sim colocá-la neste contexto social e jurídico, que não é algo inovador no Brasil, apesar de apenas em pleno século XXI, se tornar mais difundido o assunto, já que possibilita a ressignificação de valores desses povos considerados como tradicionais.

Palavras-chave: Comunidade quilombola, Negro, direitos humanos

\begin{abstract}
This article proposes a reflection on the history of the recognition of quilombo land in Brazil, specifically in the Amazon capital, without forgetting to punctuate the historical events that took place in Brazil. When it comes to official recognition of land of the Quilombo communities, can not leave the culture of these next to people, but put it in the social and legal context, which is not something new in Brazil, although only in the XXI century, become more widespread it, because it allows the redefinition of values of these people considered traditional.
\end{abstract}

Keywords: Quilombo, Black, human rights

\footnotetext{
${ }^{1}$ Mestre em Direito Ambiental pela Universidade do Estado do Amazonas -UEA, Manaus, Amazonas. Professor pelo Centro Universitário Luterano de Manaus -CEULM/ULBRA, Manaus, Amazonas, (Brasil) Email: tutortreinamneto@gmail.com ${ }^{2}$ Doutoranda em Sociedade e Cultura pela Universidade Federal do Amazonas -UFAM, Manaus, Amazonas. Professor Substituto pela Universidade Federal do Amazonas -UFAM, Manaus, Amazonas, (Brasil).
} 


\section{INTRODUÇÃO}

O conhecimento tradicional dos descendentes de escravos, precisa ser mantido e valorizado, no qual é necessário manter as tradições destes povos que ajudaram e continuam contribuindo para a história social e cultural do Brasil. Conforme Boaventura Santos a tarefa maior nestes tempos não é mais legalizar direitos humanos, torná-los lei torná-los Constituição, isso já foi feito. A tarefa maior é implementá-los, transformar o dever em ser. Na nação brasileira, a Constituição Federal de 1988, se tornou um importante passo para a implementação dos direitos fundamentais pela via judicial, com ações coletivas que beneficiam a sociedade. Através do direito ambiental, enquanto ciência, são criadas normas que tendem garantir a saúde, o equilibrio e o bem estar do meio ambiente para as futuras gerações.

A partir de então, os impasses, ou uma modernidade inconclusiva deixam anteriormente rastros não acabados no âmbito desse reconhecimento oficial de terras quilombolas, haja vista que, os descendentes de ex-escravos eram considerados como minorias sociais, mas essa realidade vem mudando através das políticas públicas.

O ser humano, embora dotado de pluralismos culturais, étnicos, antecedentes históricos, costumes e credos diversos, dentro da sua evolução, identificou valores comuns ao gênero humano sem os quais a governabilidade do sistema global certamente estaria comprometida. Esses valores foram compactados, pode-se dizer na dignidade humana geradora do reconhecimento do valor da pessoa dentro da concepção ética antropocêntrica defendida por Kant, segundo a qual o homem deve ser visto como um fim em si mesmo. (ALONSO Jr., 2006, p.18).

Agora na contemporaneidade, se torna um momento de conceder ao "excluído" a palavra, que por sinal é autoral, no sentido em que os quilombolas são autores dos seus conhecimentos, cultura, tradições e religião, portanto, são autores da sua história, contudo não é alguém que vai chegar e fazer a história destes e sim a ação coletiva da própria comunidade na luta por seus direitos.

A ação coletiva será o principal instrumento de cidadania para abrir este debate na esfera judicial, sendo esperada uma nova postura dos legitimados do Poder Judiciário para concretização do que já consta no sistema jurídico nacional, sobretudo na Constituição Federal. (ALONSO Jr., 2006, p.12).

Boaventura Santos (2008) traz para dentro de uma pesquisa científica, aquilo que chama de conhecimento tradicional onde é preciso fazer a escavação das tradições, escavar os problemas de pesquisa, ir ao rizoma das questões que são instauradas, deixando um pouco de lado esse laboratório de pesquisa cartesiano. É necessário que o pesquisador leve à Academia, 
elementos instauradores e não fique somente na teoria se tornando mero reprodutor do conhecimento. Por isso, essa pesquisa além de coletar dados bibliográficos e documentais, também verificou em campo, como se deu o reconhecimento oficial da comunidade do Barranco de São Benedito, bcalizada em Manaus, o segundo quilombo urbano do Brasil

\section{O NEGRO E SEUS DIREITOS}

Antes de abordar sobre a questão jurídica das comunidades quilombolas no Brasil, fazse necessário trazer um breve histórico da situação do negro no País. A estrutura social fundada no período pós-abolição, fez com que os ex-escravos fossem vistos como mão-de- obra barata, subalternos da sociedade, onde o negro não conseguia se adaptar e ter condições sociais adequadas na sociedade, porque lhe faltava principalmente oportunidade de ascensão, tornandose um processo excludente, onde quem tinha vez era o homem branco, entre eles os imigrantes europeus, a cor da pele falava mais alto na busca de uma oportunidade profissional.

(...) o preconceito e a discriminação racial apareceram no Brasil como conseqüências inevitáveis do escravismo. A persistência do preconceito e discriminação após a destruição do escravismo não é ligada ao dinamismo social do período pós-abolição, mas é interpretada como um fenômeno de atraso cultural, devido ao ritmo desigual de mudança das várias dimensões dos sistemas econômico, social e cultural. (HASENBALG, 1979, p.73).

O problema é que mesmo depois de 126 anos do fim da escravidão no Brasil, ainda é comum essa prática de exploração degradante em regiões distantes dos grandes centros comerciais e com dificuldades de acesso das autoridades, como por exemplo, no interior do Amazonas, onde as estradas na verdade são os rios. A falta de contingente suficiente para fiscalização é outro fator que favorece a esse tipo de crime. O trabalho análogo ao de escravo, infelizmente ainda existe de forma silenciada e aprisionadora, como revela os dados disponíveis no Portal do Ministério do Trabalho e Emprego (MTE). No ano de 2013, aproximadamente 2.063 trabalhadores foram resgatados de uma situação análoga ao de escravo no Brasil, mas para isso, foram feitas 179 operações em todo o País. Os direitos individuais dos empregados apresentam a característica especial da indisponibilidade. Segundo Delgado (2007, p.218), “alguns são absolutamente indisponíveis, não admitindo transação ou ajuste pelas partes, como o direito a assinatura da Carteira de Trabalho, salário mínimo e à incidência das normas de proteção à saúde e segurança do trabalhador”. Minas Gerais seguido de São Paulo foram os estados com maior número de trabalhadores resgatados em 2013, respectivamente 446 e 419 . Do total de resgatados, 1.068 estavam trabalhando na zona urbana. 
Pela primeira vez os regates na zona urbana superaram os da zona rural e os setores que mais preocupam são os da pecuária, agricultura e até mesmo o da construção civil.

Notadamente, a escravidão é combatida através do ordenamento jurídico brasileiro que torna crime o ato de ter pessoas trabalhando em forma parecida com a de escravos no País e penaliza este tipo de prática, mas a falta de fiscalização ainda favorece a ocorrência desse delito na sociedade, haja vista que, muitas pessoas trabalham em péssimas condições e por salários baixíssimos, muito abaixo do necessário à própria sobrevivência. Além disso, em muitos casos esses trabalhadores são impedidos de abandonar esses locais, sem quitar dívidas contraídas com os patrões, dívidas essas que às vezes se tornam impagáveis. A liberdade é um bem indisponível e imprescindível para que o ser humano alcance a sua dignidade, por esse motivo, deve o Estado promover a sua efetiva proteção, tanto em sede preventiva quanto repressiva, pois há pensamentos ultrapassados de alguns empregadores que veem, por exemplo, os gastos com a proteção do meio ambiente do trabalho como despesas e não como investimento.

E pensando sobre essas situações, que apesar de não fazer parte de sua época, mas de certa forma, já existia de forma silenciada, os primeiros trabalhos do intelectual e filósofo contemporâneo, Florestan Fernandes, tinham como objetivo proporcionar a acumulação de conhecimentos, falavam de comunidades e pequenos grupos. E por sinal, já detectava de forma incipiente, o negro como parte do povo e a cultura folclórica. Seus estudos iniciaram nas décadas de 1930 e 1940, a pesquisa prática ainda não era tão comum, como nos dias atuais, a Sociologia era considerada uma ciência empírica, onde ainda não existiam técnicas específicas para a análise e explicações dos fenômenos. Sob a influência da escola culturalista americana é que o estudo da cultura negra ganha dimensão e começam os estudos iniciais, conforme rehatam Roger Bastide e Florestan Fernandes, que por volta de 1950 iniciaram pesquisas que tinham como objetivo verificar o suposto caráter democrático das relações raciais no Brasil "A repressão às atividades sediciosas dos escravos e, principalmente, às ações rebeldes dos escravos fugidos e reunidos em quilombos, sempre foi uma preocupação dos senhores, bem como da política colonial e imperial". (BATISDE;FERNANDES, 2008, p.230).

A partir de então, fica evidente que com a promulgação Constituição de 1988, o trabalho escravo passaria a ser mais combatido, pois explorar a mão de obra das pessoas sem lhe oferecer condições mínimas de saúde e segurança violaria um dos mias importantes 
fundamentos da nova ordem jurídica do país, a dignidade da pessoa humana. A escravidão, segundo Maestri Filho (1986, p.3) pode ser definida de três maneiras.

Três determinações devem necessariamente estar presentes em uma forma de dependência social para que possamos defini-la como escravidão. O cativo, considerado como simples mercadoria, deve estar sujeito as eventualidades próprias aos bens mercantilizáveis - compra, venda, alugueres, etc. A totalidade do produto do seu trabalho deve pertencer ao senhor. A remuneração que o cativo recebe sob forma de alimento, habitação, etc., devem depender da vontade senhorial. Por último, o status escravo deve ser vitalício e transmissível aos filhos.

O trabalho em condição análoga ao de escravo, em consonância com a nova redação do art. 149 do Código Penal, estipulada pela Lei $n^{\circ}$ 10.803/2003, específica e criminaliza-o, pois é compreendido como um trabalho forçado, onde a jornada é exaustiva, e em algumas situações a servidão é feita devido à dívidas, além de se tratar de um trabalho em condições degradantes. As pesquisas sobre as relações sociais surgem depois da Segunda Abolição, porque os negros foram abandonados após a Abolição da Escravidão em 13 de maio de 1888, uma luta popular moderna, compartilhada por brasileiros de todos os tons de pele. Nesta fase, a maioria não conseguiu trabalho, as crianças passaram a ser abandonadas nas ruas, teve um aumento no índice de violência. Entretanto, os negros libertos, não estavam adaptados a uma sociedade mercantil e foram entregues à própria sorte. A investigação sobre o problema racial no Brasil faz parte da sociedade de classe, o que representa uma ruptura em relação à democracia racial. Florestan se preocupa com a Segunda Abolição, onde é necessário que haja mudanças nas leis e o protesto negro, que é considerado o verdadeiro movimento de democracia no Brasil. As suas interpretações em relação ao negro, demonstra que o preconceito racial já existia no senso comum de todos os estratos sociais no Brasil, o que torna impossível negá-lo.

(...) a sociedade brasileira largou o negro ao seu próprio destino, deitando sobre seus ombros a responsabilidade de reeducar- se e de transformar-se para corresponder aos novos padrões e ideais de homem, criados pelo advento do trabalho livre, do regime republicano e capitalista. (FERNANDES, 1978, p.20).

O desajustamento estrutural fez com que houvesse o desbcamento do negro nos mercados livres, e de certa forma gerou o preconceito racial, haja vista que por volta de 1935, os negros eram considerados como população de cor.

O processo de abolição da escravidão, fez com que a inserção do negro no cenário social acontecesse lentamente, mas a sua adaptação deveria ser rápida na sociedade onde todos deveriam ser iguais perante a lei, todavia, os cargos e funções profissionais ocupados eram 
principalmente nos setores subalternos, onde de certa forma, os negros e mulatos continuavam sendo escravos, porém livres.

Acresce que o próprio "negro" tinha de aprender a agir socialmente como trabalhador livre e a lidar com o mundo da economia urbana, sem ter tempo para isso. As coisas caminharam depressa demais. De modo que o desajustamento do "negro", que poderia ser um fenômeno transitório, converteu-se em desajustamento estrutural. Em vez de ser reabsorvido pelo sistema de trabalho urbano e pela ordem social competitiva, ele foi repelido para as esferas marginais desse sistema, nas quais se concentravam as ocupações irregulares e degradadas, tanto econômica quanto socialmente." (FERNANDES, 1972, p.113).

Com o desenvolvimento econômico no Brasil, houve a imigração, considerada como um dos fatores de aceleração do crescimento econômico, mas também favoreceu na manifestação da desigualdade racial no Brasil, principalmente por volta de 1885 a 1930. Segundo Fernandes (1972) o imigrante se introduziu em uma competição racial com o negro e o mulato.

Os grupos que contavam com posições mais ou menos vantajosas na estrutura de poder e de competição, também contavam, naturalmente, com as oportunidades mais vantajosas de participação nesses dois processos. Na verdade, como a estrutura do sistema de relações raciais excluía o "negro" de tais oportunidades, os brancos praticamente monopolizaram as vantagens dela decorrentes. Tudo isto quer dizer que a imigração apenas agravou, como e enquanto fator histórico, as diferentes expressões assumidas pela desigualdade racial na vida social do negro e do mulato. (FERNANDES, 1972, p. 127-128)

Posto isto, mesmo com a abolição da escravidão, o negro foi marcado pelas desigualdades raciais e preconceito social uma vez que o regime escravista não preparou o escravo para um trabalhador livre. Logo, os imigrantes tinham vantagens, principalmente São Paub, onde os negros eram substituídos pelo homem branco, que tinha vastas possibilidades de ascensão social diante do desenvolvimento da economia no estado. Duas províncias do Brasil aboliram a escravatura antes da Lei Áurea, Fortaleza no dia 25 de março de 1884 e o Amazonas em 10 de julho de 1884. No Amazonas, aloum tempo depois dessa data, muitos escravos foram enviados para trabalhar em uma colônia em Itacoatiara, conforme explica Baze (2001), esta era fomentada também pela apreensão de escravos contrabandeados, devido à proibição do tráfico negreiro ${ }^{1}$. Para Sakamoto (2006, p.11), o trabalho em situação análoga 
a de escravo vai além da violação dos direitos trabalhistas, pois o homem perde a sua liberdade e consequentemente a sua dignidade, pois fica sem possibilidade de sair dessa situação vexatória:

Quando falamos de trabalho escravo, estamos nos referindo a muito mais do que o descumprimento da lei trabalhista. Estamos falando de homens, mulheres e crianças que não têm garantia da sua liberdade. Ficam presos a fazendas durante meses ou anos por três principais razões: acreditam que têm que pagar uma dívida ilegalmente atribuída a eles e por vezes instrumentos de trabalho, alimentação, transporte estão distantes da via de acesso mais próxima, o que faz com que seja impossível qualquer fuga, ou são constantemente ameaçados por guardas que, no limite, lhes tiram a vida na tentativa de uma fuga. Comum é que sejam escravizados pela servidão por dívida, pelo isolamento.

Neste sentido, passamos a descrever como o Brasil busca erradicar o trabalho em condições análogas à de escravos no País, bem como estão os direitos legais das comunidades remanescentes de quilombos, já que a Constituição Federal de 1988 é sem dúvida a mais importante, pois é ela que assegura uma série de direitos e garantias fundamentais à existência de qualquer pessoa.

\section{TERRITÓRIO QUILOMBOLA}

O que torna de fato uma comunidade quilombola? Quais aspectos jurídicos que a intitulam como tal? Há vários conceitos referentes aos quilombos, que variam de acordo com a área do conhecimento. De acordo com a Secretaria Especial de Políticas de Promoção da Igualdade Racial (SEPPIR), os bcais de concentração de escravos, afastados dos centros urbanos e em locais de difícil acesso eram considerados como quilombos, a partir de então, foi construída uma identidade face à necessidade de luta pelo território e pela manutenção dos povos.

A construção de uma identidade coletiva é possível não só devido às condições sociais de vida semelhantes, mas também por serem percebidas como interessantes e, por isso, é uma construção e não uma inevitabilidade histórica ou natural. E, mais, na afirmação dessa identidade coletiva há uma luta intensa por afirmar os ,modos de percepção legítimae da (di)visão social, da (di)visão do espaço, da (di)visão do tempo da divisão da natureza. (GONÇALVES, 2003, p. 379).

\footnotetext{
${ }^{1}$ Somente em 30 de março de 1887, foi oficializada a inexistência de escravos no Amazonas, após o encerramento do livro de matrículas de escravos, na Alfândega de Manaus.(LOUREIRO, 1989, p.219).
} 
Epistemologicamente, verifica-se que com a escravidão as vantagens favorecem apenas ao patrão. Desde o início do século passado, o artigo 149 do Código Penal Brasileiro trata como crime o fato de submeter alguém às condições análogas ao de escravo. "A extensão da legislação trabalhista no meio rural tem mais de 30 anos (Lei n. 5.889 de 08/06/1973). Portanto, tanto a existência do crime como a obrigação de garantir os direitos trabalhistas não são coisas novas e desconhecidas" (OIT, 2005, p. 31). Os escravos sofreram dominação, massacres dentro das fazendas, onde "trabalhavam" e em virtude disso, muitos negros fugiam e ficavam em locais distantes conhecidos como quilombos, na condição de refugiados e a partir de então, foram erguendo suas identidades. Para Almeida (2005, p.12) a construção da identidade se dá em dois momentos: "voltar-se para si mesmos e buscar elementos essenciais para a construção da vida, desse modo de vida historicamente construído; e, em segundo, no confronto com o 'mundo de fora". Essa conceituação da identidade pode ser visualizada no Decreto $\mathrm{n}^{\circ} 4.887$, de 20 de novembro de 2003, que regulamenta o procedimento para identificação, reconhecimento, delimitação, demarcação e titulação das terras ocupadas por remanescentes das comunidades dos quilombos de que trata o art. 68 do Ato das Disposições Constitucionais Transitórias, no qual estabelece no $\S 1^{\circ}$ para os fins deste Decreto, a caracteriação dos remanescentes das comunidades dos quilombos será atestada mediante autodefinição da própria comunidade, conforme é apresentado também em seu Art. $2^{\circ}$.

Art. $2^{\circ}$. Consideram-se remanescentes das comunidades dos quilombos, para os fins deste Decreto, os grupos étnico-raciais, segundo critérios de autoatribuição, com trajetória histórica própria, dotados de relações territoriais específicas, com presunção de ancestralidade negra relacionada com a resistência à opressão histórica sofrida.

Conforme a Instrução $N^{\circ} 57$ de 20 de outubro de 2009 do Instituto Nacional de Colonização e Reforma Agrária (Incra) no Art. $3^{\circ}$, consideram-se remanescentes das comunidades dos quilombos os grupos étnico-raciais, segundo critérios de auto-definição, com trajetória histórica própria, dotados de relações territoriais específicas, com presunção de ancestralidade negra rehacionada com a resistência à opressão histórica sofrida. A caracterização dos remanescentes das comunidades de quilombos será atestada mediante autodefinição da comunidade, que garantirá a certificação.

Parágrafo único. A auto-definição da comunidade será certificada pela Fundação Cultural Palmares, mediante Certidão de Registro no cadastro Geral de Remanescentes de Comunidades de Quilombos do referido órgão, nos termos do $\S 4$, do Art. $3^{\circ}$, do Decreto $\mathrm{n} 4.887$, de 20 de novembro de 2003. 
Para uma comunidade ser reconhecida como quilombola, é necessário ser feita a autoidentificação de descendentes de escravos, por meio de entrevistas feitas por integrantes do Governo Federal às familias residentes no local a ser considerado quilombo. A outra forma de se autodecharar como quilombola é a partir do cultivo positivo de manifestações culturais, religiosas e sociais de ações que demonstrem heranças culturais negras e passam a ser reconhecidas nos dois aspectos citados como comunidades remanescentes quilombola. A legislação infraconstitucional também contempla a proteção das comunidades quilombolas, com a Lei $\mathrm{n}^{\mathrm{o}}$ 13.123, de 2015, regulamenta o inciso II do $\S 1$ e e $\S$ 4o do art. 225 da Constituição Federal o Artigo 1, a alínea j do Artigo 8, a alínea c do Artigo 10, o Artigo 15 e os $\S \S 30$ e 4o do Artigo 16 da Convenção sobre Diversidade Biológica, promulgada pelo Decreto no 2.519, de 16 de março de 1998; dispõe sobre o acesso ao patrimônio genético, sobre a proteção e o acesso ao conhecimento tradicional associado e sobre a repartição de benefícios para conservação e uso sustentável da biodiversidade; revoga a Medida Provisória no 2.18616, de 23 de agosto de 2001; e dá outras providências, conforme o Art. $2^{\circ}$.

Art. $2^{\circ}$ Além dos conceitos e das definições constantes da Convenção sobre Diversidade Biológica - CDB, promulgada pelo Decreto no 2.519, de 16 de março de 1998, consideram-se para os fins desta Lei:

II - conhecimento tradicional associado - informação ou prática de população indígena, comunidade tradicional ou agricultor tradicional sobre as propriedades ou usos diretos ou indiretos associada ao patrimônio genético;

III - conhecimento tradicional associado de origem não identificável conhecimento tradicional associado em que não há a possibilidade de vincular a sua origem a, pelo menos, uma população indígena, comunidade tradicional ou agricultor tradicional;

IV - comunidade tradicional - grupo culturalmente diferenciado que se reconhece como tal, possui forma própria de organização social e ocupa e usa territórios e recursos naturais como condição para a sua reprodução cultural, social, religiosa, ancestral e econômica, utilizando conhecimentos, inovações e práticas geradas e transmitidas pela tradição.

Com essa Lei, o Estado reconhece o direito de populações indígenas, de comunidades tradicionais e de agricultores tradicionais de participar da tomada de decisões, no âmbito nacional, sobre assuntos relacionados à conservação e ao uso sustentável de seus conhecimentos tradicionais associados ao patrimônio genético do País, nos termos desta Lei e do seu regulamento. Portanto, a identificação dos limites das terras das comunidades remanescentes de quilombos é feita a partir de indicações da própria comunidade, bem como a partir de estudos técnicos e científicos, inclusive relatórios antropológicos, consistirá na caracteriação 
espacial, econômica, ambiental e sócio-cultural da terra ocupada pela comunidade, mediante Relatório Técnico de Identificação e Delimitação (RTID), com elaboração a cargo da Superintendência Regional do Incra, que o remeterá, depois de concluído, ao Comitê de Decisão Regional, para decisão e encaminhamentos subsequente. O relatório antropológico intitulado Cartografia da Amazônia, foi elaborado no ano de 2004, através da iniciativa do Prof. Dr. Alfredo Wagner Berno de Almeida, a partir de um projeto de iniciação cientifica feito na Universidade do Estado do Amazonas (UFAM), tendo como objetivo dar ensejo à autocartografia dos povos e comunidades tradicionais na Amazônia, especificamente a Comunidade do Barranco da Praça 14 de Janeiro em Manaus, juntamente com as iniciativas da Associação do Movimento Orgulho Negro do Amazonas (Amonam).

Todo movimento social se configura a partir daqueles que rompem a inércia e se movem, isto é, mudam de lugar, negam o lugar que historicamente estavam destinados em uma organização social, e buscam ampliar os espaços de expressão que, como já nos alertou Michel Foucault, têm fortes implicações de ordem política. (GONÇALVES, 2001, p. 81).

Desse modo, foi feito o cadastramento das 25 familias remanescentes de comunidades de quilombos, após o preenchimento de formulários específicos do Incra. Além de ser feito um levantamento detalhado da área pleiteada que posteriormente, gerou um parecer conclusivo da área técnica e jurídica sobre a proposta do território, bcalizado na Avenida Japurá, bairro Praça 14 de Janeiro, zona Centro-Sul de Manaus.

\section{LEGISLAÇÃO FEDERAL}

Apesar de estar presente no Art. 68 da Constituição Federal de 1988, a primeira titulação de terra quilombola ocorreu no Brasil somente no ano de 1995, através da Portaria Incra n. ${ }^{\circ}$ 307, de 22 de novembro de 1995, sete anos depois a promulgação da Carta Magna, o que torna de certa forma, um direito reconhecido recentemente. Neste período, considerou-se que caberia ao INCRA a administração das terras públicas desapropriadas por interesse social, discriminadas e arrecadadas em nome da União Federal, bem como a regularização das ocupações nelas havidas na forma da lei. De acordo com a Portaria, assinada pelo presidente do Incra na época, Francisco Graziano Neto, as ações de reforma agrária conduzidas pelo Estado visavam a promoção plena do homem, preservando seus valores sociais e culturais, integrandoo às peculiaridades de cada região, propiciando uma relação racional e equilibrada nas suas interações com o meio ambiente, conforme os itens a seguir:

I - Determinar que as comunidades remanescentes de quilombos, como tais caracterizadas, insertas em áreas públicas federais, arrecadadas ou obtidas 
por processo de desapropriação, sob a jurisdição do INCRA, tenham suas áreas medidas e demarcadas, bem como tituladas, mediante a concessão de título de reconhecimento, com cláusula "pro indiviso", na forma do que sugere o art. 68 do Ato das Disposições Constitucionais Transitórias da Constituição Federal;

II - Facilitar a criação do Projeto Especial QUILOMBOLA, em áreas públicas federais arrecadadas ou obtidas por processo de desapropriação para atender aos casos de comunidades remanescentes de quilombos, com títulos de reconhecimento expedidos pelo INCRA;

III - Recomendar que os projetos especiais sejam estruturados de modo a não transigir em relação ao "status quo" das comunidades beneficiárias, em respeito às condições suscitadas pelo art. 68 do Ato das Disposições Constitucionais Transitórias, e artigos 215 e 216 da Constituição Federal;

IV - Determinar à Diretoria de Assentamento que defina instruções normativas, mecanismos e meios indispensáveis à criação e implementação dos projetos especiais quilombola, de modo a assegurar a consecução dos fins por estes almejados;

V - Incumbir a Diretoria de Assentamento de adotar as providências objetivando orçamentar, provisionar e controlar os recursos destinados ao atendimento dos projetos especiais Quilombolas;

VI - Esta Portaria entra em vigor na data da sua publicação, revogadas as disposições em contrário.

Logo, os primeiros passos para a titulação de terras quilombolas no Brasil, se deu por meio da Portaria 307 do Instituto Nacional de Colonização e Reforma Agrária (Incra) que determinava que as comunidades quilombolas tivessem suas áreas demarcadas e tituladas, Artigo 68 do Ato das Disposições Transitórias, Artigos 215 e 216 da Constituição Federal de 1988. A partir do reconhecimento da função social da propriedade, esta perde seu caráter absoluto, devendo cumprir certos fins para gozar de proteção constitucional. Mas, a Portaria 307 vigorou até o mês de outubro do ano de 1999, pois a $11^{\text {a }}$ reedição da Medida Provisória $n^{\circ}$ 1.911-11/99, delegou ao Ministério da Cultura (MinC) a competência para titular as terras quilombolas, através da Fundação Cultural Palmares (FCP), vinculada ao MinC criado e institucionalizado pela Lei $\mathrm{n}^{\circ}$. 7.688, de 22 de agosto de 1988, no qual atua no etnodesenvolvimento das comunidades remanescentes de quilombos, bem como na preservação e difusão do patrimônio cultural e imaterial afrobrasileiro.

Entretanto, pouco mais de um mês depois da publicação da MP $\mathrm{n}^{\circ} 1.911$ 11/99, era o Ministério da Cultura quem editava sua própria portaria interna (Portaria MinC $\mathrm{n}^{\circ}$ 447), oficializando a FCP como único órgão federal competente pelo gerenciamento de processos de reconhecimento e titulação dos territórios quilombolas. Um ano mais tarde, em dezembro de 2000, uma nova medida provisória iria "corrigir"a lei de criação da Fundação Palmares (7.688/88), incluindo um parágrafo sobre a competência inalienável desta 
instituição sobre assuntos relacionados aos remanescentes de quilombo no Brasil. (MENINO, 2010, p.79).

Em 10 de setembro de 2001, o presidente do Brasil, Fernando Henrique Cardoso, editou o Decreto $\mathrm{n}^{\mathrm{o}} 3.912$, estabelecendo que somente as terras ocupadas por quilombos a partir do ano de 1888 e as que estavam ocupadas por remanescentes em 5 de outubro de 1988, poderiam receber o tínub oficial de terras. Em virtude disso, houve uma paralisação no Decreto $\mathrm{n}^{\mathrm{o}} 3.912 / 2001$ e nenhuma terra de comunidade quilombola foram regularizadas na vigência desse decreto. Haja vista, que os principais prejudicados pela medida foram os quilombolas de áreas de conflito que na data da promulgação da Constituição não se encontravam na posse de seus territórios, além dos demais que pretendiam se regularizar.

Com isso, houve manifestos e reivindicações em busca da titularidade, e somente no dia 20 de novembro de 2003, o novo presidente do Brasil, Luís, Inácio Lula da Silva, fez com que o Decreto $n^{\circ} 3.912 / 2001$ fosse revogado pelo Decreto $n^{\circ} 4.887$, de 20 de novembro de 2003, cuja finalidade era retomar com as titulações e um dos itens adotados foi conduzir o processo de titulação novamente ao Incra, conforme os artigos:

Art. $1^{\circ}$ Os procedimentos administrativos para a identificação, o reconhecimento, a delimitação, a demarcação e a titulação da propriedade definitiva das terras ocupadas por remanescentes das comunidades dos quilombos, de que trata o art. 68 do Ato das Disposições Constitucionais Transitórias, serão procedidos de acordo com o estabelecido neste Decreto.

Art. $3^{\circ}$ Compete ao Ministério do Desenvolvimento Agrário, por meio do Instituto Nacional de Colonização e Reforma Agrária - INCRA, a identificação, reconhecimento, delimitação, demarcação e titulação das terras ocupadas pelos remanescentes das comunidades dos quilombos, sem prejuízo da competência concorrente dos Estados, do Distrito Federal e dos Municípios.

$\S 1^{\circ} \mathrm{O}$ INCRA deverá regulamentar os procedimentos administrativos para identificação, reconhecimento, delimitação, demarcação e titulação das terras ocupadas pelos remanescentes das comunidades dos quilombos, dentro de sessenta dias da publicação deste Decreto.

$\S 2^{\circ}$ Para os fins deste Decreto, o INCRA poderá estabelecer convênios, contratos, acordos e instrumentos similares com órgãos da administração pública federal, estadual, municipal, do Distrito Federal, organizações nãogovernamentais e entidades privadas, observada a legislação pertinente.

O Instituto Nacional de Colonização e Reforma Agrária (Incra) faz vigorar a Instrução N 57 de 20 de outubro de 2009 para regulamentar o procedimento para identificação, reconhecimento, delimitação, demarcação, desintrusão, titulação e registro das terras ocupadas por remanescentes das comunidades dos quilo mbos. 


\subsection{TERRITÓRIO QUILOMBOLA E A SUBJETIVIDADE JURÍDICA}

A primeira Lei de Terras, escrita e lavrada no Brasil, é de 1850, e excluía os africanos e seus descendentes da categoria de brasileiros, situando-os numa outra categoria separada, denominada "libertos" e por isso continuam lutando pelas suas terras em todo o Brasil

A quilombagem foi apenas uma das formas de resistência. Outras, como o assassínio dos senhores, dos feitores, dos capitães-de-mato, o suicídio, as fugas individuais, as guerrilhas e as insurreições urbanas se alastraram por todo o período. Mas o quilombo foi a unidade básica de resistência do escravo. (MOURA, 1981, p.14).

Na contemporaneidade, o quilombo representa um direito a ser reconhecido, tornando se uma pauta na política nacional, diante do artigo 68 da Constituição Federal que prevê o reconhecimento da propriedade das terras dos remanescentes, no entanto, há uma preocupação não só social, mas econômica e ambiental As terras de quilombos devem ser remetidas à formalização jurídica das terras de uso comum, ou seja, domínios doados, entregues ou adquiridos, concessões feitas pelo estado, áreas de apossamento ou doadas em retribuição aos serviços prestados, conforme explica o antropólogo Alfredo de Almeida (1998) no que tange as terras utilizadas por agricultores familiares.

$\mathrm{O}$ da unidade familiar que suporta um certo processo produtivo singular, que vai conduzir ao acamponesamento com o processo de desagregação das fazendas de algodão e cana de açúcar e com a diminuição do poder de coerção dos grandes proprietários territoriais (ALMEIDA,1998, p.8).

De acordo com dados atualizados até julho de 2015 pela Fundação Cultural Palmares (FCP), entidade vinculada ao Ministério da Cultura (MinC), que busca contribuir para a vabrização das manifestações culturais negras brasileiras como patrimônios nacionais, no País as Certidões Expedidas às Comunidades Remanescentes de Quilombos (CRQs) iniciaram no ano de 2004 e neste período o estado do Maranhão foi o único estado brasileiro com o maior número de comunidades quilombolas, chegando a 158 e concedidas seis certidões. Enquanto que no mesmo período, na região Norte, apenas os estados do Pará (18 comunidades), Rondônia (01 comunidade) e Tocantins (01 comunidade), possúam comunidades remanescentes de quilombos reconhecidos, totalizando 20, na regão Norte. No primeiro semestre de 2015, havia 319 comunidades quilombolas na região Norte, registrada pela Fundação Cultural Palmares, já no fim do segundo semestre houve um aumento de aproximadamente $3 \%$, onde o número de comunidades passou para 328. Logo, considera-se que em todas as regiões do Brasil, houve um aumento de $2 \%$ nas certidões emitidas e o total de 
comunidades passou a ser 2648, gerando um aumento de $2 \%$ de acordo com dados divulgados até 31 de dezembro de 2015. Posto isto, verifica-se que ao todo já foram emitidas mais de 2.470 certificações pela Fundação Cultural Palmares, onde a região Nordeste lidera (62\%), seguida da regão Sudeste (14\%), Norte (12\%), Sul (7\%) e Centro-Oeste (5\%).

Conforme a definição do Instituto Nacional de Cobnização e Reforma Agrária (INCRA) disponível no site da instituição ${ }^{2}$ as comunidades quilombolas são grupos étnicos predominantemente constituídos pela população negra rural ou urbana -, que se autodefinem a partir das relações com a terra, o parentesco, o território, a ancestralidade, as tradições e práticas culturais próprias. "A vida social e econômica das regiões manifesta-se pelos fenômenos que resultam da colaboração ou da luta entre o homem e a terra". (TOCANTINS, 2000, p.209). Com isso, os direitos coletivos das populações invisíveis estão dispostos na Constituição Federal Brasileira, através de artigos como o 215, §1 - "O Estado protegerá as manifestações culturais populares, indígenas e afro-brasileiras, e das de outros grupos participantes do processo civilizatório nacional". E o Artigo 68 dos Atos das Disposições Constitucionais Transitórias que garantiu os direitos coletivos das comunidades remanescentes de quilo mbo, conforme explica Almeida (2004):

Através das lutas destes povos por reconhecimento, os Estados reconheceram em suas Constituições, a partir da década de 80, os direitos coletivos das populações chamadas invisíveis ocasionando mudanças tanto no campo epistemológico como no campo político. (ALMEIDA, 2004, p.44).

Esta pesquisa busca fazer um panorama a respeito das kgislações e interpretações jurídicas que pontuam sobre o direito das comunidades remanescentes de quilombos, além de conhecer em campo os modos de organização jurídica, social e cultural da Comunidade do Barranco.

Segundo os moradores da Praça 14 de Janeiro em Manaus da Comunidade do Barranco e/ou São Benedito (Vide Foto 01), técnicos do Instituto Nacional da Colonização e Reforma Agrária (INCRA) listaram todos os membros da comunidade, que já existe há mais de cem anos. Os comunitários neste caso se autodeclararam negros, e posteriormente foi solicitado via requerimento ao Ministério do Desenvolvimento Agrário (MDA), o seu reconhecimento. A partir daí desencadeou algumas etapas, para o reconhecimento do quilombo, desde o mapeamento da área, pois quem dá a titulação de terras é o INCRA.

\footnotetext{
${ }^{2}$ QUILOMBOLAS, Etapas da Regularização. INCRA. <http://www.in cra.gov.br/estruturafundiaria/quilombolas>. Acesso em 30 ago. 2014
} 


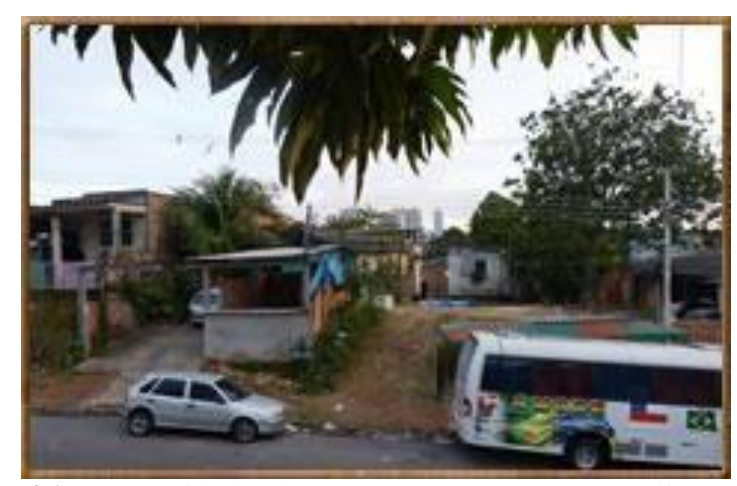

Foto 01: Comunidade do Barranco e/ou São Benedito

Fonte: Acervo dos pesquisadores (2015)

O território da Comunidade Quilombola do Barranco é constituído por um terreno de barro em parte, e asfaltado. Foi certificado pela Portaria $\mathrm{n}^{\circ} 84$, de 08 de junho de 2015 a Fundação Cultural Palmares (FCP), no qual foi concedida a Certidão Expedida às Comunidades Remanescentes de Quilombos (CRQs).

\section{CONCLUSÕES}

De tudo que foi explanado, verifica-se que o Estado do Amazonas possui sete (07) Comunidades Remanescentes de Quilombos certificadas. Entre elas constam A Comunidade do Tambor que fica entre os municípios de Barcelos (Distante a 399 quilômetros de Manaus em linha reta) e Novo Airão (Distante a 115 quilômetros de Manaus em linha reta); no município de Barreirinha (Distante a 331 quilômetros de Manaus em linha reta) há quatro comunidades reconhecidas: Boa Fé, Ituquara, Tereza do Matupiri e Trindade; em Itacoatiara (Distante a 176 quilômetros de Manaus em linha reta) consta a Comunidade do Sagrado Coração de Jesus do Lago de Serpa e em Manaus a Comunidade do Barranco. No bairro da Praça 14 de janeiro vivem familias remanescentes de escravos vindos do Maranhão, que se orgulham de suas raízes e tradições passadas de geração a geração, tendo como comemoração a festa significativa e religiosa de São Benedito, que é realizada desde a chegada dos primeiros negros alforriados em Manaus. E no mês de setembro do ano de 2014, a Comunidade do Barranco de São Benedito recebeu o certificado de reconhecimento oficial de quilombo urbano, tornando-se o segundo do Brasil. Além disso, é considerada como Patrimônio Imaterial de Manaus, por meio da Lei Estadual N. ${ }^{\circ} 4.201$, de 23 de julho de 2015, que dechara:

Art. $1^{\circ}$ Fica declarado como Patrimônio Cultural Imaterial do Estado do Amazonas, o Quilombo Urbano do Barranco de São Benedito, localizado na Rua Japurá, 1360, Bairro Praça 14 de Janeiro.

Art. $2^{\circ}$ Cabe ao Poder Executivo a adoção das medidas cabíveis para o registro de bem imaterial, nos termos da legislação pertinente. 
Art. $3^{\circ}$ Esta Lei entra em vigor na data de sua publicação.

Foi considerado um processo rápido, porque todos os documentos comprobatórios estavam em mãos dos moradores. A partir de então, se tornaram uma associação, conhecida como Associação do Movimento Orguho Negro do Amazonas (Amonam), mas ainda não possuem uma sede fixa, haja vista, que as reuniões são realizadas nas casas dos próprios moradores. Para se obter uma certificação como comunidade quilombola é necessário fazer uma assembleia com a comunidade, ou por meio de uma associação, que no caso dos descentes de escravos da Praça 14 de Janeiro, foi por meio do Amonam, através de ata, onde os comunitários se auto-declararam como remanescente de quilombo.

Burocracia, desconhecimento e preconceito operam no sentido contrário à cidadania dos quilombolas. Atualmente, os descendentes de escravos e negros lutam pela valorização da sua identidade cultural da sua igualdade racial, porque a Amazônia não se baseia apenas em economia, emprego e renda, mas também através das expressões culturais disponíveis nas festividades.

\section{REFERÊNCIAS}

ABREU, Ivy de Souza; BUSSINGUER, Elda Coelho de Azevedo. Antropocentrismo, Ecocentrismo e Holismo: Uma breve análise das escolas de Pensamento Ambiental Revista Derecho y Cambio Social: 2013.

ALMEIDA, A. W. B., et. al. Comunidade Negra de São Benedito da Praça 14 de Janeiro. Manaus-Amazonas: Projeto Nova Cartografia Social da Amazônia, 2007.

ALMEIDA, Alfredo Wagner Berno de. Amazônia: a dimensão política dos "conhecimentos tradicionais". In Acserald Henri Conflitos ambientais no Brasil. Rio de Janeiro: Relume Dumará/ Fundação Heinrich Boll, 2004.

ALMEIDA, Alfredo W. B. de. Os Quilombos e as Novas Etnias: É Necessário que nos Libertemos de Definições Arqueológicas. Vitória, Reunião da Aba, Mimeo, 1998.

ALMEIDA, A.B. (2005). Barragens no Contexto Quilombola Identidade, Luta e Modernização:O caso dos Quilombos do Vale do Ribeira - SP - Depto de Geografia, FFLCH - USP Apresentação: I Encontro Ciências Sociais e Barragens.

ARENDT, Hannah. A condição humana. Rio de Janeiro: Forense, 2003.

ALONSO Jr., Hamilton. Direito Fundamental ao Meio Ambiente e Ações Coletivas. São Paulo: Editora Revista dos Tribunais, 2006.

BANDEIRA, Maria de Lourdes. Território negro em espaço branco. São Paub: Editora Brasiliense, 1988. 346 p. 
BAZE, Abrahim. Escravidão: o Amazonas e a Maçonaria edificam a história. Manaus: Travessia, 2001.

BRASIL. Portaria $\mathbf{N}^{0}$ 104, de 23 de setembro de 2014. Diário Oficial da União, Brasilia, DF, 24 set. 2014. Disponível em URL: $<$ http://www.jusbrasil.combr/diarios/77122315/dousecao-1-24-09-2014-pg-21> Acesso em 10 mai 2015.

BRASIL. Decreto $\mathbf{n}^{\mathbf{0}} \mathbf{4 . 8 8 7}$, de 20 de novembro de 2003.Disponível em: <http:/www.planalto.gov.br/ccivil_03/decreto/2003/D4887.htm\#art25> Acesso em 20 fev. 2016.

BRASIL. LEI $\mathbf{N}^{\circ}$ 13.123, DE 20 DE MAIO DE 2015. Disponível em: $<$ http $/ /$ www.planalto.gov.br/ccivil_03/_Ato2015-2018/2015/Lei/L13123.htm\#art50> Acesso em 24 fev. 2016.

BRASIL. Decreto $\mathbf{n}^{\mathbf{0}} \mathbf{3 . 9 1 2}$, de 10 de setembro de 2001. Disponível em: <http//www.planalto.gov.br/ccivil_03/decreto/2001/D3912.htm> Acesso em 20 fev. 2016.

BRASIL. Decreto Lei no 2.848 de 7 de dezembro de 1940. Código Penal Brasileiro. Congresso Nacional, Brasilia, 1940 - alterado peh Lei $n^{\circ} 10.803$ de 11 de dezembro de 2003. Disponível em: <www.planalto.gov.br> Acesso em 26 jul 2014.

BARROS, A. J.; LEHFELD, N. A. S. Fundamentos de metodologia científica: um guia para iniciação científica. 2.ed. São Paub: Markron Books, 2000.

BOFF, Leonardo. Ecologia, mundialização e espiritualidade. São Paulo: Ática, 1993.

DA MATTA, Roberto. A casa \& a rua: espaço, cidadania, mulher e morte no Brasil. Rio de Janeiro, Rococó, 1997.

DA MATTA, Roberto. Carnavais, malandros e heróis: para uma sociologia do dilema brasileiro. - 6 ed. Rio de Janeiro: Rococo, 1997.

DECLARAÇÃO de Johannesburg sobre Desenvolvimento Sustentável 2002. Disponível em: $<$ www.mma.gov.br/estruturas/agenda21/_arquivos/joanesburgo.doc $>$. Acesso em $04 \mathrm{dez}$ 2015 .

DELGADO, Maurício Godinho. Curso de direito do trabalho. 6 $6^{\text {a }}$ ed. São Paulo: LTr, 2007, pág. 218.

DWYER, Eliane Cantarino O. Quilombos: identidade étnica e territorialidade. Rio de $\begin{array}{lllll}\text { Janeiro } & \text { Editora } & \text { FGV, } & 2002 . & \text { Disponível }\end{array}$ em: $<$ http://www.abant.org.br/conteudo/livros/Quilombos.pdf $>$ Acesso em: 10 jan. 2016.

FCP - Quadro geral de comunidades remanescentes de quilombos (CRQS). Disponível em: $<$ http $/ /$ www.palmares.gov.br/wp- content/upbads/2016/01/tABELA_CRQs_COMPLETAAtualizada-31-12-15.pdf $>$ Acesso em: 10 jan. 2016.

FERNANDES, Florestan. A Integração do Negro na Sociedade de Classes. vol 1 e 2. São Paulo: Àtica, 1978.

FERNANDES, Florestan. O negro no mundo dos brancos. São Paulo: Difel 1972. FENSTERSEIFER, Tiago. Direitos Fundamentais e proteção do ambiente: a dimensão 
ecológica da dignidade humana no marco jurídico-constitucional do Estado Socioambiental de Direito. Porto Alegre: Livraria do Advogado, 2008.

FIORILlO, Celso Antonio Pacheco. Curso de direito Ambiental Brasileiro. 10 ed. rev., atual e ampl São Paulo: Saraiva, 2009.

Paulo: Saraiva, 2013.

Curso de direito Ambiental Brasileiro. 14 ed. rev., atual e ampl São

GONÇALVES, Carlos Walter Porto. Geografando nos varadouros do mundo. Brasilia: IBAMA, 2003.

GONÇALVES, Carbs Walter Porto. Geo-grafías. Movimientos sociales nuevas territorialidades y sustentabilidad. México: Siglo XXI, 2001.

HASENBALG, Carlos. Discriminação e Desigualdades Raciais no Brasil. Rio de Janeiro: Graal, 1979.

INCRA. Quilombolas, Etapas da Regularização. Disponível em: $<$ http//www.incra.gov.br/estrutura-fundiaria/quilombolas>. Acesso em 30 ago. 2014

INCRA. Instrução Normativa $\mathbf{N}^{\circ} 57$ de 20/10/2009. Disponível em: $<$ http//www.incra.gov.br/inst itucionall/le gislacao--/atos- internos/instrucoes/file/243instrucao-normativa-n-57-20102009> Acesso em 20 fev. 2016.

LIMA, Gustavo F. da Costa. Revista Eletrônica "Política e Trabalho"- Setembro 1997/ p.201-202.

LOUREIRO, Antônio José Souto. O Amazonas na época imperial. 2. ed. Manaus: T.Loureiro Ltda., 1989.

MACHADO, Paulo Affonso Leme. Direito Ambiental Brasileiro. 2007

MAESTRI FILHO, Mario José. O escravismo antigo. São Paulo: Unicamp, 1986.

MELO, Sandro Nahmias. Meio ambiente do trabalho e greve ambiental. Revista Anamatra. v. 18. no. 54, .p. 47-53,2008.

LTr, 2001.

Meio Ambiente do Trabalho: Direito Fundamental. São Paulo:

MENINO, Frederico. Mobilizando Oportunidades: Visões sobre o recente movimento social quilombola .Biblioteca 24 horas. São Paulo - SP, 2010.

MILARÉ, Édis. Direito do Ambiente: doutrina, prática, jurisprudência, glossário. $1^{\mathrm{a}}$ ed. São Paulo: Revista dos Tribunais, 2001.

MILARÉ, Édis; COIMBRA, José de Ávila Aguiar. Antropocentrismo x Ecocentrismo na Ciência Jurídica. In: Revista de Direito Ambiental. 2004.

Direito do Ambiente: doutrina, prática, jurisprudência, glossário. $1^{\text {a }}$ ed. rev.atual ampl São Paulo: Revista dos Tribunais, 2001, p. 63. Isabella Franco Guerra, Ação Civil Pública e Meio Ambiente. 2ª reimp. Rio de Janeiro: Forense,1999. 
MOREIRA, Danielle Andrade. Dano ambiental extrapatrimonial. Dissertação de Mestrado apresentada ao Programa de Pós-Graduação em Direito da UERJ, área de concentração Direito da Cidade, em janeiro de 2003.

MOURA, Clóvis. Rebeliões na Senzala, Quilombos, Insurreições, Guerrilhas. São Paulo, Ed. Ciências Humanas, 1981.

MTE. MTE divulga balanço do trabalho escravo em 2013. Disponível em: $<$ http//portal.mte.gov.br/imprensa/mte-divulga-balanco-do-trabalho-escravo-em2013/palavrachave/trabalho-escravo-balanco.htm> . Acesso em 20 de dez. de 2015.

OLIVEIRA, Fernando Andrade de. Proteção jurídica do meio ambiente. Revista Direito Administrativo, Rio de Janeiro, 187:82-89, jan/mar, 1992.

OLIVEIRA, Leinad Ayer de. (Org.). Sobre as datas e as competências no Decreto no 3.912/2001. Quilombos: a hora e a vez dos sobreviventes. São Paulo: Comissão Pró-Índio de São Paulo, 2001.

ONU. Declaração do Rio de Janeiro sobre o meio ambiente e desenvolvimento (eco-92). Disponível em: 〈http://www.onu.org.br/rio20/img/2012/01/rio92.pdf $>$. Acesso em 02 mar. 2016.

.Resolução no 37/7 da Assembleia Geral. 1982. Disponível em: <http//www.un.org/documents/ga/res/37/a37r007.htm>. Acesso em: 01 fev 2016.

PHILIPPI JR, Arlindo; RODRIGUES, José Eduardo Ramos. Uma introdução ao Direito Ambiental: conceitos e princípios. In: PHILIPPI JR, Arlindo; ALVES, Alaôr Caffé (org.). Curso interdisciplinar de direito ambiental. Barueri-SP: Manol, 2005.

SARLET, Ingo Wolfgang. A eficácia dos direitos fundamentais: uma teoria geral dos direitos fundamentais na perspectiva constitucional. Porto Alegre: Livraria do Advogado, 2009.

SAMPAIO, Patrícia M. (org.). O fim do silêncio - presença negra na Amazônia. Belém: Açaí / CNPq, 2011.

SANTOS, Antônio Silveira Ribeiro dos. Direito Ambiental: Surgimento, Importância e Situação Atual. ln: BITTAR, Eduardo C. 8. (org.) História do Direito Brasileiro: kituras de ordem jurídica nacional São Paulo: Atlas, 2006.

SEPPIR. Comunidades Quilombolas. Disponível em: $<$ http://www.seppir.gov.br/comunidades-tradicionais/programa-brasil-quilombola>

Acesso em 23 fev. 2016.

SILVA, José Afonso da. Direito Constitucional Ambiental. São Paub: Revista dos Tribunais, 1989.

SILVA,Tatiana Dias; GOES, Fernanda Lira. Igualdade racial no Brasil: reflexões no ano internacional dos afrodescendentes/organizadoras. - Brasilia: Ipea, 2013.

SILVA, Olmiro Ferreira da. Direito Ambiental e ecologia: aspectos filosóficos contemporâneos / Olmiro Ferreira da Silva. Barueri, SP: Manole, 2003. 
SANTOS, Boaventura de Sousa. Um discurso sobre as ciências / Boaventura de Sousa Santos.5. ed. - São Paulo : Cortez, 2008.

SOUSA, Rabindranath V.A. Capelo de. O direito geral da personalidade. Coimbra, editora Coimbra, 1995.

TEPEDINO, Gustavo. A função social da propriedade e o meio ambiente. Revista Trimestral de Direito Civil, v. 37. p. 127-148, 2009

WOLKMER, Maria de Fátima Schumacher e PAULITSCH, Nicole da Silva. O estado de direito socioambiental e a governança ambiental: Ponderações acerca da judicialização das política públicas ambientais e da atuação do Poder Judiciário. Revista NEJ - Eletrônica, Vol 18 - n. 2 - p. 256-268 / mai-ago 2013. 